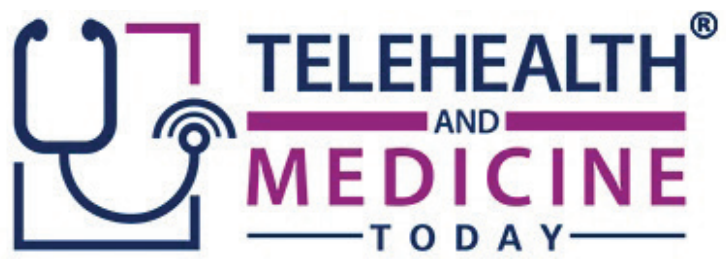

\title{
Healthcare Providers Are Missing Opportunities to Capture Data that Support Population Health Programs
}

\author{
Allison M. Hart
}

Corresponding Author: Allison M. Hart, Email: amhart@west.com

Keywords: Population Health, Healthcare Surveys, Data, Patients, Chronic Conditions

Category: Opinions, Perspectives, and Commentary

Data aggregation is important at every stage of population health management. A surprisingly

simple (and often overlooked) way by which healthcare teams can collect data and gain the insights they need to successfully execute population health plans is to leverage healthcare surveys like health risk assessment surveys, medication adherence surveys, remote health monitoring surveys and gaps in care surveys. A pair of West Corporation surveys found many providers and healthcare organizations can do a better job using surveys to prop up their population health initiatives. In particular, teams can take advantage of opportunities to use surveys to help prevent and manage chronic conditions across high-risk, rising-risk, and lowrisk subpopulations of patients.

$\mathrm{T}$ This article shares findings from two West Corporation surveys related to revenue cycle management. The first, a consumer survey conducted in partnership with Kelton Global, was administered to 1036 nationally representative Americans aged 18 years and over.
It was conducted between February 13 and February 16, 2018, using an email invitation and an online survey. The margin of error for this consumer survey is $\pm 3.1 \%$.

The second survey, a healthcare provider survey, was administered by the West Corporation and captured viewpoints from 312 healthcare providers in the United States. It was conducted between February 26 and March 11, 2018, using an email invitation and an online survey. The margin of error for this provider survey is $\pm 6 \%$.

\section{BACKGROUND}

Improving clinical outcomes, increasing care quality, and controlling costs are primary objectives of population health management. To inform population health strategies that support these objectives, healthcare providers and organizations need data and insights about their patients. One option for capturing data is to utilize healthcare surveys to gather information on health risks, medication adherence, remote health monitoring, and gaps in care. 
Surveys are simple for healthcare teams to administer, and according to a West Corporation consumer survey of 1036 adults in the United States, a majority of patients are willing to complete them. However, few healthcare teams are using surveys to prop up population health initiatives. The West Corporation's provider survey revealed, for example, that only 11 percent of healthcare providers are using survey check-ins to remotely monitor patients' health (Table 1). As a result, they are missing opportunities to capture data and insights that can be used to improve health outcomes for different patient populations.

Many providers and organizations already have the technology needed to execute surveys.
By making surveys part of their population health programs and using survey data alongside electronic medical records (EMRs), teams can better manage the health of target populations, including high-risk, rising-risk, and low-risk patient groups.

\section{MONITORING MEDICATION USE} AMONG HIGH-RISK POPULATIONS

Effectively managing the health of high-risk patients (who need help controlling diseases and preventing complications) can be a challenging part of population health management. To make the task a bit easier, healthcare teams can use medication adherence surveys. Because so many high-risk patients require medication to help control diseases, medication adherence

Table 1. The West Corporation's provider survey revealed that $86 \%$ of patients would likely take a survey from a healthcare provider if asked. However, healthcare surveys are not widely used by providers and healthcare organizations

\begin{tabular}{|l|l|}
\hline $\begin{array}{l}\text { Key Findings from Consumers } \\
\text { post-discharge surveys following } \\
\text { hospitalizations. }\end{array}$ & $\begin{array}{l}\text { Only } 9 \% \text { of healthcare teams use surveys to monitor } \\
\text { symptoms or pain after patients have been discharged } \\
\text { from the hospital. }\end{array}$ \\
\hline $\begin{array}{l}\text { 83\% of patients are interested in taking } \\
\text { health risk assessment surveys. }\end{array}$ & $\begin{array}{l}\text { Just } 12 \% \text { of healthcare teams use surveys to collect } \\
\text { information about health symptoms, conditions, and } \\
\text { behaviors that can be used to identify health risks. }\end{array}$ \\
\hline $\begin{array}{l}\text { Nearly } 8 \text { in } 10 \text { Americans (79\%) with a } \\
\text { chronic illness are interested in participating } \\
\text { in remote health monitoring surveys. }\end{array}$ & $\begin{array}{l}\text { Only } 11 \% \text { of healthcare teams use survey check-ins } \\
\text { to remotely monitor patients' health. }\end{array}$ \\
\hline $\begin{array}{l}\mathbf{7 8 \%} \text { of patients are interested in participating } \\
\text { in gaps in care surveys. }\end{array}$ & $\begin{array}{l}\text { Just 7\% of healthcare teams use surveys to regularly } \\
\text { monitor key metrics that indicate how well patients } \\
\text { are managing conditions (e.g., blood sugar levels and } \\
\text { blood pressure) }\end{array}$ \\
\hline $\begin{array}{l}\mathbf{7 4 \%} \text { of patients are interested in taking } \\
\text { medication adherence surveys. }\end{array}$ & $\begin{array}{l}\text { Only } 9 \% \text { of healthcare providers use online surveys } \\
\text { to check in with patients and see if they are taking } \\
\text { medications as instructed. Even fewer providers use } \\
\text { surveys to monitor patients' medication use following } \\
\text { hospitalizations (7\%) and to learn about the side effects } \\
\text { patients are experiencing from medications (7\%). }\end{array}$ \\
\hline
\end{tabular}


surveys are particularly useful for supporting high-risk groups.

Medication adherence surveys can be used to collect data to show if high-risk patients are taking medications correctly, what barriers are preventing patients from taking prescribed medications, and when interventions are necessary to support patients for better disease management. Unfortunately, medications for chronic conditions are taken incorrectly (or not at all) approximately half of the time. ${ }^{1}$ Asking high-risk patients to complete medication adherence surveys helps providers learn what is keeping patients from taking medications so healthcare teams can address that issue.

Healthcare providers may want to use medication adherence surveys to ask high-risk patients the following questions:

- Did you fill your prescription?

- Is cost, transportation or another factor prohibiting you from picking up your medication?

- Have you been taking your medication as prescribed?

- Do you have difficulty remembering to take your medication?

- Are you experiencing any side effects that could cause you to stop taking your medication?

- Would you like to speak to a member of your healthcare team about concerns or questions you have about your medication?

Using survey responses as a guide, providers can design population health solutions targeted toward patients' needs. Teams can set up automated medication reminders and send them to patients who forget to take medications. Providers can contact patients who are struggling with the cost of medication and discuss cheaper alternatives. These types of interventions are proven to produce positive results. One study found that patients who received medication reminder interventions (medication reminder calls) following a hospitalization were more adherent after 12 months than patients who did not receive the same engagement communications $(89 \% \text { vs. } 74 \%)^{2}$

The West Corporation's provider survey revealed that only $9 \%$ of healthcare providers currently use online surveys to check in with patients and see if they are taking medications as instructed. Even fewer providers use surveys to monitor patients' medication use following hospitalizations (7\%) and to learn about the side effects patients are experiencing from medications (7\%). Many more providers and organizations could employ medication (and other) surveys to support high-risk patient groups and fuel population health efforts. According to the West Corporation's consumer survey findings, $74 \%$ of Americans are interested in taking medication adherence surveys. The point is that surveys have the potential to help high-risk patients, but patients need to be given the opportunity to take them.

\section{SUPPORTING DISEASE PREVENTION AMONG RISING-RISK PATIENTS}

Rising-risk patients come with their own unique challenges. Because they don't yet have complex health issues or chronic diseases, but they have been identified as being at risk of developing them, rising-risk patients demand proactive care. Otherwise, they can quickly become high-risk patients. To support rising-risk patients and help prevent them from becoming sicker, healthcare providers can use remote health monitoring surveys. 
Using the same patient engagement technology they use for appointment reminders, healthcare teams can send patients invitations to complete online monitoring surveys. As an example, patients with prediabetes might be asked to complete a remote health monitoring survey that prompts them for the following information:

- Enter their weight

- Take a blood pressure reading and report the results

- Submit a blood glucose reading

- Indicate how much physical activity they get each week

- Report average number of times they use cigarettes daily

Collecting information like this makes it easier for providers to recognize when patients are struggling and when additional support is needed. It helps teams monitor for red flags between appointments so they can intervene sooner rather than later.

Unfortunately, like with medication adherence surveys, remote health monitoring surveys are not widely used. Only $11 \%$ of healthcare providers say they administer online survey check-ins. This is despite nearly eight in ten Americans with a chronic illness (79\%) saying they are interested in participating in remote health monitoring surveys. Again, providers are missing population health management opportunities.

\section{KEEPING LOW-RISK PATIENTS HEALTHY}

Although low-risk patients are typically very healthy, they can benefit from population health initiatives too. And, like with other patient groups, surveys provide healthcare teams with information they can use to help low-risk patients achieve their best possible health.
As low-risk patients tend to visit their healthcare providers infrequently, healthcare teams usually don't have much insight into their health. However, if there is one thing that providers know about low-risk patients, it's that prevention is the key to protecting their health. That makes gaps in care surveys ideal for lowrisk patients.

A gap in care survey asks patients questions to identify healthcare services (e.g., well visits, blood pressure checks, cancer screenings, and immunizations) they may have missed. Asking a group of low-risk patients to complete a gaps in care survey is an easy way to identify patients needing screenings and services that are important for preventing chronic conditions and other health issues. Having this extra check in place helps providers give patients more complete preventive care experiences, which is important for keeping low-risk patients healthy.

According to the West Corporation's consumer survey, $78 \%$ of patients are interested in participating in gaps in care surveys, but healthcare teams aren't using these surveys widely. Many more healthcare providers can (and should) use gaps in care surveys to identify which preventive services low-risk patients need and then schedule appointments.

\section{SURVEY IMPLEMENTATION \\ CHALLENGES AND SOLUTIONS}

One challenge healthcare organizations must overcome if they want to leverage surveys to support population health management is to learn how to capture data from patients and extrapolate actionable insights. Healthcare teams may have a better grip on how to do that than they realize, particularly if they use patient satisfaction surveys to measure performance and drive 
process and facility improvements. The process for developing surveys and inviting patients to take them is similar regardless of whether a satisfaction survey, medication survey or some other type of survey is being used. In planning their survey, the following questions should be considered:

- What type of survey will be most useful?

- What patient segment the survey will be sent to?

-What is the best timing for delivering the survey? (e.g., a weekly recurring survey or a check-in after a patient is released from the hospital)

- What information needs to be collected from patients to inform population health management?

After that, teams can create online surveys and use their patient engagement technology to deliver survey invitations.

Another challenge for healthcare teams is to convince patients to take surveys. As pointed out earlier, most patients are willing to participate in surveys from healthcare providers. In fact, $86 \%$ of patients who participated in the West Corporation's consumer survey indicated that they would likely take a survey from a healthcare provider if asked. So, getting patients to take surveys may be less of a challenge than what providers perceive. By following some survey best practices (e.g., creating surveys that patients can take on their own time from any device), healthcare teams should be able to draw a good response from patients.

\section{CONCLUSIONS}

Clearly, there is a place for surveys in population health management. Unfortunately, surveys are missing from a lot of population health management programs. Introducing surveys isn't difficult. Those healthcare teams who make surveys part of population health management and use them to capture information from patients can feel more confident that their population health efforts are data-driven and match the needs of patients.

Funding statement: There was no funding associated with this project.

Conflict of Interest: The author declares no competing interests with respect to research, authorship, and/or publication of this article.

Contributors: Allison M. Hart.

\section{REFERENCES}

1. Viswanathan M, Golin CE, Jones CD, Ashok M, Blalock SJ, Wines RC. Interventions to Improve Adherence to Self-administered Medications for Chronic Diseases in the United States: A Systematic Review. Ann Intern Med. Available from: http://annals.org/aim/fullarticle/1357338/ interventions-improve-adherence-selfadministered-medications-chronic-diseasesunited-states

2. Neiman AB, Ruppar T, Ho M. CDC grand rounds: Improving medication adherence for chronic disease managementInnovations and opportunities. MMWR. 2017;66. http://dx.doi.org/10.15585/mmwr. mm6645a2

Copyright Ownership: This is an open access article distributed in accordance with the Creative Commons Attribution Non Commercial (CC BY-NC 4.0) license, which permits others to distribute, adapt, enhance this work non-commercially, and license their derivative works on different terms, provided the original work is properly cited and the use is noncommercial. See: http://creativecommons. org/licenses/by-nc/4.0. 